\title{
Bilgisayarlı tomografide insidental olarak saptanan meme lezyonları
}

\author{
Incidentally detected breast lesions on computerized tomography
}

\author{
İsmet Miraç Çakır, Hatice Ayça Ata Korkmaz, Eser Bulut, Nahide Gökçe Çakır
}

\section{Özet}

Amaç: Mamografi memenin başlıca görüntüleme metodu olmasına rağmen, farklı patolojik bulguları saptamak için yapılan toraks bilgisayarlı tomografilerde (BT) insidental benign ve malign meme lezyonları saptanması giderek artmaktadır. Bu nedenle, bu lezyonların saptanması ve doğru olarak tanımlanması önemlidir. Bu çalışmada, meme dışı patolojilerin saptanması için yapılan BT'lerde meme lezyonlarının morfolojik özelliklerini değerlendirmeyi amaçladık.

Gereç ve yöntem: 2010-2018 tarihleri arasında hastanemizin patoloji bölümü veritabanı araştırılarak histopatolojik tanısı olan ve toraks BT çekimi yapılmış olan 20 malign ve 12 benign lezyon bulundu. Benign gruba ultrasonografi ya da mamografide en az 2 yıllık takipte stabil lezyonu bulunan ve toraks BT'si bulunan 8 hasta eklendi. Toraks BT'de 20 malign, 20 benign lezyonu olan 40 hasta retrospektif olarak incelendi. Meme lezyonlarının morfolojik özellikleri, kontrastlanma paterni ve patolojik LAP varlığı değerlendirildi.

Bulgular: Toraks BT'de 20 malign lezyonun 19 (\%95)'u, 20 benign lezyonun 19 (\%95)'u tespit edilmiştir. Malign lezyonların 18'i düzensiz, 1 'i oval şekildeydi. Kitle kontürü ise 10'unda düzensiz, 8'inde spiküle, 1 'inde ise düzgün sınırlıydı. Benign lezyonların 13'ü oval, 4'ü yuvarlak, 2'si ise düzensiz şekilliydi. Kitle kontürü 14'ünde keskin, 4'ünde düzensiz, 1'inde ise spiküle idi. Malign lezyonların tümünde, benign lezyonlarında ise $6(\% 31,6)$ 'sında kitle kontrastlanması mevcuttu. Malignite tanılı $5(\% 26,3)$ hastada aynı tarafta malign görünümlü lenfadenopati (LAP) tespit edildi. Benign tanılı hastalarda eşlik eden patolojik görünümlü LAP saptanmadı.

Sonuç: BT'de ortaya çıkan özellikler benign lezyonları malignlerden ayırt etmeye yardımcı olabilir. Toraks BT'de insidental kontrastlanan meme lezyonunun düzensiz kontür ve şekli, eşlik eden patolojik LAP'ının olması maligniteyi, düzgün kontur ve şeklinin olması kitlede kontrast tutulumunun olmaması benigniteyi düşündürmelidir.

Anahtar Kelimeler: Bilgisayarlı Tomografi, meme, toraks.

Çakır IM, Ata Korkmaz HA, Bulut E, Çakır NG. Bilgisayarlı tomografide benign ve malign meme lezyonlarının morfolojik özellikleri. Pam Tıp Derg 2019;12:77-82.

\begin{abstract}
Purpose: Despite the fact that mammography is the main imaging method, incidental benign and malignant breast lesions are increasingly detected in thorax computerized tomography (CT) to detect different pathologic findings. For this reason, it is important that these lesions are identified and correctly identified. In this study, we aimed to evaluate morphologic features of breast lesions in CT scans for the detection of non-mammary pathologies.

Materials and methods: Between 2010 and 2018, 20 malignant and 12 benign lesions with histopathologic diagnosis and thoracic CT scans were searched in the pathology department database of our hospital. Eight patients with benign grouped ultrasonography or mammography with at least 2 years follow-up stabl lesion and thorax CT were included. Thirty patients with 20 malignant and 20 benign lesions on CT were retrospectively reviewed. Morphologic features of breast lesions, contrast pattern and pathological LAP were evaluated.

Results: 19 (95\%) of 20 malignant lesions and 19 (95\%) of 20 benign lesions were detected in thorax CT. 18 of malignant lesions were irregular and 1 of them was oval. The mass contour was irregular in 10, spicule in 8 , and smooth in 1.13 of benign lesions were oval, 4 were round, 2 were irregular. Mass contour was sharp in 14 , irregular in 4, and spicule in 1. Massive enhancement was present in all malignant lesions and in $6(31.6 \%)$ benign lesions. Malignant lymphadenopathy (LAP) was diagnosed in 5 patients $(26.3 \%)$. Patients with benign diagnoses were not associated with pathologic LAP.

Conclusion: The features of MDCT can help to differentiate benign lesions from malignancies. The incidence of incidental enhancement breast lesion in thorax CT is irregular contour and shape, accompanied by pathologic
\end{abstract}

İsmet Miraç Çakır, Uzm. Dr. Sağlık Bilimleri Üniversitesi, Kanuni Eğitim ve Araştırma Hastanesi, Radyoloji Bölümü, TRABZON, e-posta:ismetcakir_55@hotmail.com (orcid.org/0000-0002-4229-7493) (Sorumlu yazar)

Hatice Ayça Ata Korkmaz, Dr. Öğr. Üyesi, Sağlık Bilimleri Üniversitesi, Kanuni Eğitim ve Araştırma Hastanesi, Radyoloji Bölümü TRABZON, e-posta:dr.h.aycaatakorkmaz@gmail.com (orcid.org/0000-0001-9987-3351)

Eser Bulut, Uzm. Dr. Sağlık Bilimleri Üniversitesi, Kanuni Eğitim ve Araştırma Hastanesi, Radyoloji Bölümü TRABZON, e-posta:eserbulutmd@ gmail.com (orcid.org/0000-0002-6765-6552)

Nahide Gökçe Çakır, Arş. Gör. Dr. Karadeniz Teknik Üniversitesi Tıp Fakültesi, Farabi Hastanesi, Aile Hekimliği Ana Bilim Dalı, TRABZON, e-posta:gokce_basmaci@hotmail.com (orcid.org/0000-0001-8096-3971) 
LAP malignancy, smooth contour and shape, absence of mass contrast enhancement should suggest benignity.

Keywords: Computerized Tomography, breast, thorax.

Çakır IM, Ata Korkmaz HA, Bulut E, Çakır NG. Morphological features of benign and malignant breast lesions in computerized tomography. Pam Med J 2019;12:77-82.

\section{Giriş}

Mamografi, ultrasonografi ve manyetik rezonans görüntüleme (MRG) meme lezyonlarının teşhisinde kullanılan temel radyolojik yöntemlerdir [1].

Meme değerlendirmesinde potansiyel klinik uygulamalar için özel meme bilgisayarlı tomografi (BT) araştırılmış olsa da, spesifik meme lezyonlarını değerlendirmek için birincil yöntem olarak düşünülmemiştir. Toraks BT, rutin olarak akciğer, mediasten, plevra, göğüs duvarı ve diyaframa ait hastalıkları araştırmak için kullanılmakta olup primer olarak meme dokusunu taramak için kullanılmaz. Bununla birlikte, tüm meme dokusu genellikle toraks BT incelemesinde görülür. Teşhis veya tarama amacıyla toraks BT' nin artan kullanımı ile birlikte, tesadüfen ortaya çıkan meme lezyonlarıyla giderek daha fazla karşılaşılmaktadır. Bazı olgularda, BT meme lezyonunu gösteren ilk görüntüleme modeli olabilir [2].

Ayrıca, bazı meme kanseri tipleri, enflamatuar meme kanseri gibi BT'de mamografiye oranla daha iyi görülebilir. Ayrıca, ülsere meme lezyonları olan hastalarda, BT uygulamak çok daha kolaydır. Buna ek olarak, aksiller bölgede yer alan ve göğüs duvarına yakın konumlanmış meme kanserlerinin saptanmasında BT, mamografiden daha iyi görüntüleme sağlayabilir.

Literatürde toraks BT'de meme lezyonlarının morfolojik özelliklerini değerlendiren az sayıda araştırma bulunmaktadır. Bu çalışmanın amacı, BT 'nin meme lezyonlarının tanısında yeterliliğini değerlendirmek ve $\mathrm{BT}$ ' de benign-malign lezyonların morfolojik özelliklerini belirlemektir.

\section{Gereç ve yöntem}

Çalışmamızda kurumsal yerel etik komite onayı (2017/61) alındı. 2010-2018 yılları arasında radyoloji kliniğimizde 20584 toraks BT incelemesi yapıldı. Sağlık merkezimizin patoloji ve radyoloji bölümleri veritabanları araştırılarak histopatolojik tanısı olan ve meme dışı hastalıklar nedeniyle toraks BT incelemesi yapılan 20 malign ve 12 benign meme lezyonu olan 32 hasta bulundu. Benign gruba ultrasonografi ya da mamografide en az 2 yıllık takipte stabl lezyonu bulunan ve meme dışı hastalıklar nedeniyle toraks BT incelemesi yapılan 8 hasta eklendi. Toraks BT >de 20 malign, 20 benign lezyonu olan 40 hasta retrospektif olarak incelendi.

Mammografi ve sonografik muayene sonrasında bir ay içinde BT görüntülemesi olmayan hastalar çalışmaya dahil edilmedi.

$\mathrm{Bu}$ çalışmada altın standart tanı yöntemi olarak histopatolojik veriler ve muhtemel benign lezyonlar için en az 24 ay süresince radyolojik ve klinik takiplerde stabilite olarak kabul edidi.

Supin pozisyonda 64-detektörlü bir MDBT tarayıcı (Aquilion 64; Toshiba Medical Systems, Otawara, Tochigi, Japonya) kullanılarak, 300 mg / mL'lik non iyonik kontrast maddenin (Ultravist lopromide) otomatik enjektör sistemi ile 2 ile $6 \mathrm{~mL} / \mathrm{dk}$ 'larda intravenöz uygulama sonrası toraks BT incelemesi gerçekleştirildi. Tarama, kontrast maddesinin enjeksiyonundan 50 saniye sonra gerçekleştirildi.

Çalışmaya dahil edilen 40 hastanın, BT görüntüleri iki deneyimli radyolog (sırasıyla meme görüntülemede 11 ve 21 yıllık tecrübe deneyimi) tarafından retrospektif olarak gözden geçirildi. İncelemelerde toraks BT>de meme lezyonlarının varlığı hakkında bilgileri vardı; Bununla birlikte meme lezyonlarının lokalizasyonları ve tanıları hakkında bilgileri yoktu.

Okuyuculardan, kontrastlı BT'de saptanan meme lezyonlarının, boyutu, şekli, kontur özellikleri ve kontrastlanma paternlerini tanımlamaları istendi. Kör değerlendirmede tanımlanan kitlelerin lokalizasyonunun doğruluğu daha sonra ultrason ve mamografi ile doğrulandı. Lezyonların şekli yuvarlak, ovoid, düzensiz kitle olarak, kontürü ise düzgün, düzensiz ve spiküle olarak tanımlandı. Kontrastlanan lezyon normal meme dokusundan daha fazla atenuasyon gösteren lezyon olarak kabul edilmiş olup kontrastlanma paternine göre 
homojen, heterojen ve halkasal kontrastlanma olarak 3 gruba ayrılmıştır. Çalışma alanı içerisindeki aksiller lenf nodları değerlendirildi ve uzun aksın kısa aksı oranı <2 olan veya düzensiz kortikal kalınlaşma olduğu takdirde anormal kabul edildi. Meme parankim yapısı, stromal ve glandüler yapı miktarına dayalı olarak mamografi için Amerikan Radyoloji Koleji (ACR) tarafından tanımlanan sınıflandırmaya göre sınıflandırılmıştır.

İstatistiksel analiz için Windows 21 SPSS (SPSS Inc, Chicago, Illinois, ABD) yazılım paketi kullanılmıştır. Tanımlayıcı değerler, kategorik veriler için sayı ve yüzde olarak ve nitel veriler için aritmetik ortalama sstandart sapma olarak sunulmuştur. Malign ve benign lezyonların boyutları arasındaki değişkenliği değerlendirmek için Wilcoxon testi kullanıldı. Anlamlılık $p<0,05$ olarak belirlenmiştir.

\section{Bulgular}

Çalışma grubu yaş ortalaması $52,95 \pm 11,9$ (32-81 yıl) olan 40 kadındı. 40 hastanın 20 > sinde (\%50) malign bulgular, 20»sinde (\%50) benign bulgular vardı. 20 malign hastada en sık görülen patoloji invaziv duktal karsinom idi (18 hasta,\%90). 1 hastada invaziv lobüler karsinom ve 1 hastada duktal karsinoma in sutu tanısı vardı (Tablo 1). Hastaların hepsinin cerrahi sonrası patoloji tanıları vardı. Benign tanılı 20 hastanın 12 sinin ultrasonografi eşliğinde tru-cut biyopsi sonucu vardı. 8 hastanın benignite tanısı en az 2 yıllık ultrasonografi takibi ile koyuldu. Biyopsi sonuçlarında 6 hastada fibroadenom, 1 hastada fibrokistik değişim, 1 adenozis, 1 papillom, 1 hafif epitelyal hiperplazi, 1 non-nekrotizan granülom, 1 lenfoid doku tanısı aldı (Tablo 2). Toraks BT incelemesinde 20 malign kitleden $19(\% 95)>u$, benign kitlelerden de 20 kitleden 19 (\%95)>u okuyucular tarafından tespit edilmiştir. Malign lezyonların ortalama boyutu 25,32 \pm 18 mm (7-72 $\mathrm{mm}$ ) iken, benign lezyonların ortalama boyutu $14,53 \pm 8,5 \mathrm{~mm}$ (7-46 mm) idi. Ortalama malign ve benign meme lezyonu boyutu arasında anlamlı fark yoktu $(p=0,68)$. Malign lezyonların 18 'i düzensiz, 1'i oval şekildeydi (Resim 1). Kitle konturü ise 10'unda düzensiz, 8'inde spiküle, 1 'inde ise düzgün sınırlıydı. Benign lezyonların 13'ü oval, 4'ü yuvarlak, 2'si ise düzensiz şekilliydi (Resim 2, 3). Kitle konturu 14'ünde keskin, 4'ünde düzensiz, 1'inde ise spiküle idi. Malign lezyonların 19'unda kontrastlanma mevcut olup, 15'i heterojen, 2'sinde homojen, 2'sinde halkasal kontrastlanma mevcuttu (Resim 4). Benign lezyonların ise 6'sında kontrastlanma olup 4'ünde homojen 2'sinde heterojen kontrastlanma mevcuttu. Malignite tanılı beş hastada aynı tarafta malign görünümlü lenfadenopati (LAP) tespit edildi. Benign tanılı hastalarda eşlik eden patolojik görünümlü LAP saptanmadı (Tablo 3).

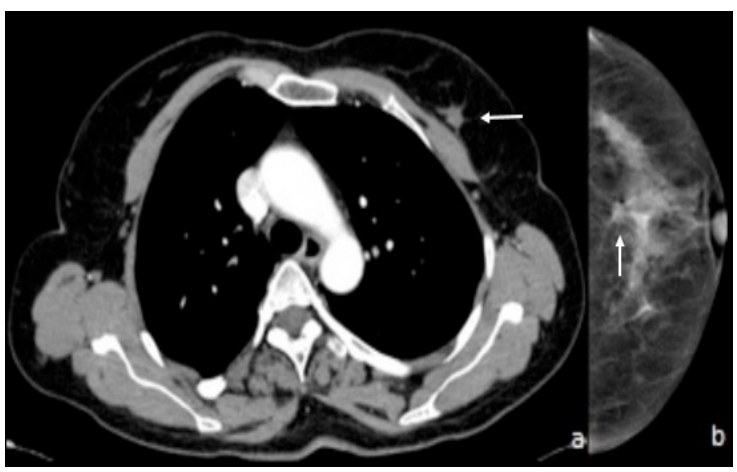

Resim 1. Aksiyal BT görüntüsü (a) ve sol CC projeksiyon mamografi görüntüsü (b), sol memenin üst dış kadranda (oklar) spiküle kontürlü kitle izlenmektedir. Patoloji sonucu invaziv duktal karsinom.

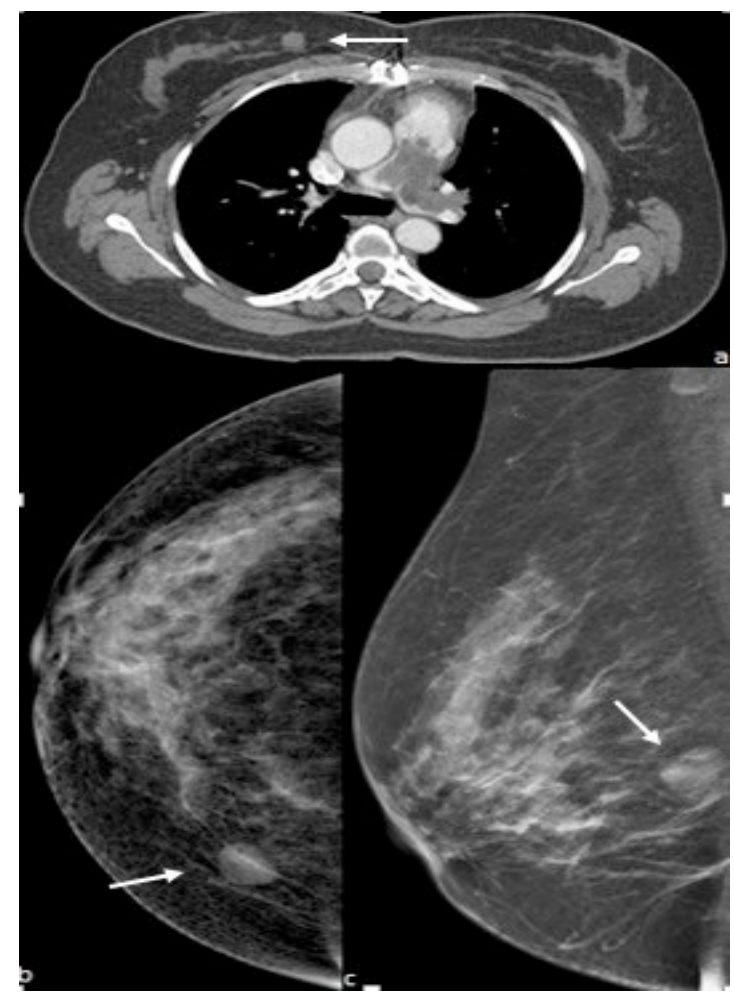

Resim 2. Aksiyal BT görüntüsü (a) ve sağ $C C$ ve MLO projeksiyon mamografi görüntüleri (b), sağ meme orta iç kadranda (oklar) oval şekilli düzgün sınırlı kitle izlenmektedir. Tru-cut biyopsi tanısı fibroadenom. 
Tablo 1. Malign Lezyonlar

\begin{tabular}{ll}
\hline Tanı & Sayı $(\mathrm{n} \%)$ \\
\hline İnvaziv duktal karsinom & $18(90)$ \\
İnvaziv lobuler karsinom & $1(5)$ \\
Duktal karsinoma in situ & $1(5)$ \\
\hline
\end{tabular}

Tablo 2. Benign Lezyonlar

\begin{tabular}{ll}
\hline Tanı & Sayı $(\mathrm{n} \%)$ \\
\hline Fibrokistik Hastalık & 1 \\
24 aylık takipte stabl lezyon & 8 \\
Fibroadenom & 6 \\
Adenozis & 1 \\
Benign Papiller Lezyon & 1 \\
Hafif Epitelyal Hiperplazi & 1 \\
Non nekrotizan Granülom & 1 \\
Lenfoid Doku & 1 \\
\hline
\end{tabular}

Tablo 3. Benign ve Malign Kitlelerde Lezyon Morfolojileri

\begin{tabular}{lll}
\hline Morfolojik Bulgular & Malign & Benign \\
Boyutlar & 25,32 & 14,53 \\
Şekil & & \\
Oval & $1(5,3)$ & $13(68,4)$ \\
Yuvarlak & $18(94,7)$ & $4(21,1)$ \\
Düzensiz & - & $2(10,5)$ \\
Kontur & & \\
Keskin & $1(5,3)$ & $14(73,7)$ \\
Düzensiz & $10(52,6)$ & $4(21,1)$ \\
Spiküle & $8(42,1)$ & $1(5,3)$ \\
Kontrastlanma Özelliği & & \\
Homojen & $2(10,5)$ & $4(21,1)$ \\
Heterojen & $15(78,9)$ & $2(10,5)$ \\
Halkasal & $2(10,5)$ & - \\
Yok & - & $13(68,4)$ \\
Patolojik LAP & $5(26,3)$ & - \\
Tüm lezyonlar & $19(100)$ & $19(100)$ \\
\hline
\end{tabular}

LAP: Ienfadenopati 


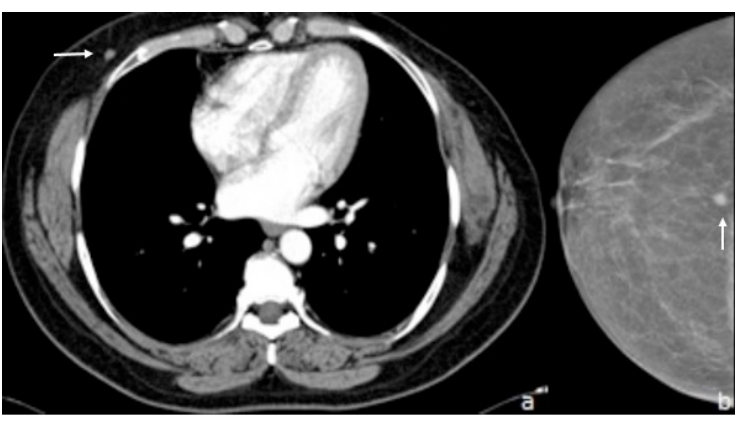

Resim 3. Aksiyal BT görüntüsü (a) ve sağ CC projeksiyon mamografi görüntüsü (b), Sağ meme retroaerolar hatta oval şekilli düzgün sınırlı kitle izlenmektedir. Kitle mamografi ve sonografi ile 3 yıllık takipte stabl olup boyut artışı ve morfolojik özelliklerinde değişiklik göstermedi.

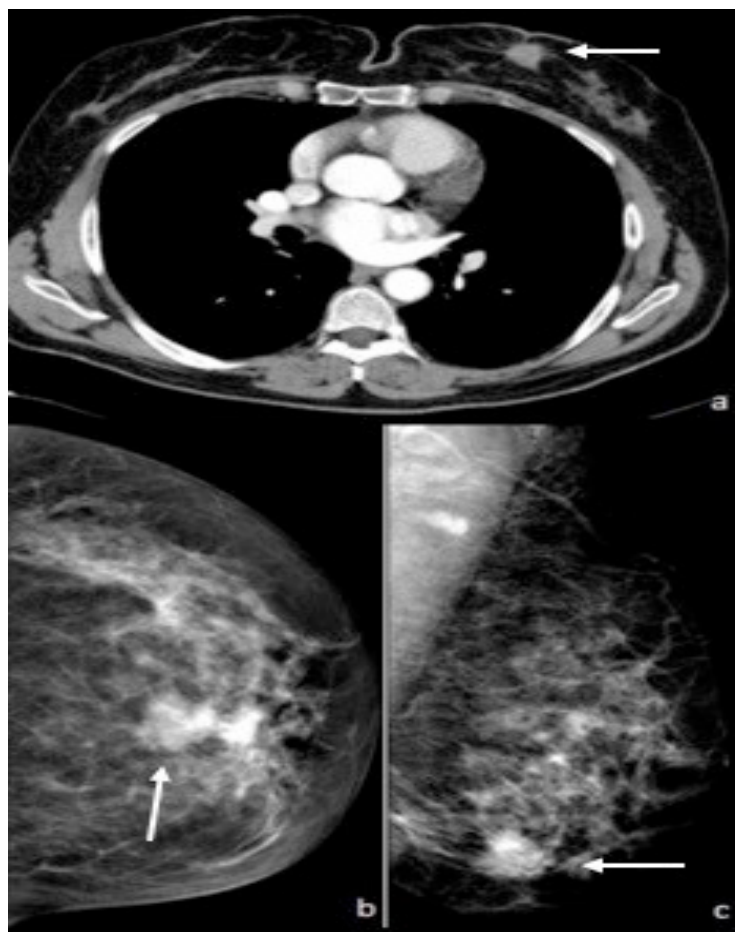

Resim 4. Aksiyel BT görüntüsü (a) Sol CC ve MLO projeksiyon mamografi görüntüleri $(b, c)$. Sol meme alt iç kadranda düzensiz kontürlü kitle izlendi. Patoloji sonucu invaziv duktal karsinom.

\section{Tartışma}

Rutin toraks BT incelemeleri genellikle meme hastalığı dışındaki endikasyonlar için yapılmış olsa da insidental meme lezyonları zaman zaman saptanabilmekte, bazı olgularda ise toraks BT'de insidental meme kanseri saptanabilir.
Swensen ve ark. [3], akciğer kanseri taraması için yapılan toraks BT incelemesinde 735 kadından üçünde $(\% 0,4)$ meme kanseri vakası rapor etmişlerdir. Shojaku ve ark [4], toraks BT incelemesi yapılan 1008 hastadan 4'ünde $(\% 0,4)$ insidental meme kanseri veya metastatik meme karsinomu olgusunu bildirmişlerdir. Yakın zamanda yapılan bir çalışmada, 432 toraks BT incelemesinde sekiz (\%2) rastlantısal primer meme kanseri tespit edilmiştir [5].

Bizim çalışmamızda, meme dışı hastalıklar nedeniyle toraks BT incelemesi yapılan hastaların $\% 0,2$ oranında insidental meme kitlesi bulunmaktaydı. Toraks BT tetkiki gerçekleştirilen hastalarda insidental meme kanseri saptama oranımız literatürü destekler niteliktedir.

Toraks BT'de benign ve malign meme lezyonlarını ayırt etmek için radyolojik tanı kriterleri gereklidir. Literatürde, bazı yazarlar BT'de meme kanseri tanısında en spesifik özellik olarak düzensiz şekil, spiküle kontur yapısı, halkasal kontrastlanma ve aksiller lenfadenopati bildirmiş olsalar da [6, 7], bu kriterlere uymayan ve benign bulgulara benzerlik gösteren malign meme tümörleri de bildirilmiştir [8, 9]. İnvaziv duktal karsinom erken evrede yoğun kontrast tutulumu gösteren spiküle kontürlü lezyonlar şeklinde, lobüler karsinom ise bazen deri kalınlaşması veya düzensiz kenarlı asimetrik yoğunluk artışı şeklinde kendini gösterir. Spesifik olmayan meme lezyonları için ek değerlendirmeler gereklidir [5].

Çalışmamızda malign lezyonların 18 $(\% 94,7)$ 'inde spiküle kontür ya da düzensiz sınır vardı. Malign kitlelerden invaziv duktal karsinom tanısı bulunan bir lezyonda BTıde oval şekil ve düzgün sınır mevcuttu. Bu nedenle, önceki çalışmalarda da vurgulandığı gibi, insidental saptanan düzgün sınırlı meme lezyonlarının da ileri değerlendirmelere yönlendirilmesi gerektiği ileri sürülmektedir.

BT'de benign lezyonların $14 \quad(\% 73,7)$ 'ü düzgün kontürlüydü. 4'ünde düzensiz kontür ve 1'inde spiküle kontur yapısı vardı. Düzensiz kontür yapısına sahip benign lezyonların $1^{\prime \prime} i$ hafif epitelyal hiperplazi, 1 'i fibroadenom, 1 'i papillom, 1'i de takipte stabl lezyondu. Spiküle kontür yapısına sahip benign lezyonun ise adenosiz tanısı vardı. Adenozis ve hafif epitelyal hiperplazi tanılı lezyonların kitle şekli düzensizti. 
Genel olarak, malign lezyonlarda en önemli bulgular düzensiz ve spiküle kontur yapısına sahip olan düzensiz şekilli lezyonlar, benign lezyonlarda ise en önemli bulgular düzgün sınırlı oval ya da yuvarlak şekilli lezyonlardır.

Lin ve ark. [2] yapmış olduğu çalışmada, malign meme lezyonu olan 16 hastada, 10 (\%63) lezyonda heterojen kontrastlanma, altı lezyonda (\%38) ise homojen kontrastlanma saptamışlardır. Benign meme lezyonu bulunan yedi hastanın üçünde (\%43) heterojen kontrastlanma, dördünde $(\% 57)$ ise homojen kontrastlanma saptamışlardır. Inoue ve ark. [10] çalışmasında, malign lezyonlarda homojen ve halkasal kontrastlanma, heterojen kontrastlanmaya oranla fazla bulunmuştur.

Malign lezyonların hepsinde kontrast tutulumu izlenmekte olup en çok heterojen kontrastlanma paterni mevcuttu. Benign lezyonların sadece 6'sında kontrast tutulumu mevcut olup homojen kontrastlanma en sık görülen kontrastlanma paterniydi.

Erken fazda kontrastlanan malign lezyonlar rutin toraks BT'lerde saptanabilir. Bazı benign lezyonlar ise erken fazda yeterli kontrast tutulumunun olmaması nedeniyle saptanamayabilir.

Çalışmamızda okuyucular, BTıde malign lezyonu bulunan 5 hastada patolojik LAP tespit etmiş olup doğruluğu cerrahi patoloji sonuçları ile kanıtlanmıştır. Bu bulgular, BTıde aksiller, supraklaviküler ve derin pektoral kas bölgelerinin tamamının kesit alanına girmesi ve BTınin yüksek kontrast çözünürlüğüyle açıklanabilir.

Çalışmamızın en önemli kısıtıııkları arasında öncelikle radyologların meme lezyonlarından haberdar olması ve çalışma tasarımının retrospektif olması, ikinci olarak ise tüm hastaların histopatolojik tanılarının bulunmaması sayılabilir. Bununla birlikte, benign meme lezyonu olan 8 hastada 24 aylık takipte stabilite muhtemelen benign tanısı için yeterliydi. Son olarak, kontrastlı toraks BT incelemelerimiz sadece arteriyel fazda elde edildiğinden ve kontrastsız görüntülerin bulunmaması sebebiyle lezyonların zaman içerisinde kontrastlanma paternlerini değerlendiremedik.

Sonuç olarak, BT'de malignite için en önemli göstergeler, düzensiz şekilli ve düzensiz yada spiküle kontürlü lezyonların varlığı ve lenfadenopati idi. BT'de oval ya da yuvarlak şekilli düzgün sınırlı lezyonlar genellikle benign lezyonlara karşılık gelir. Meme lezyonlarının BT görüntüleme bulgularının bilinmesi ve toraks BT tetkiklerinde, görüntüleme alanına giren memenin daha dikkatli bir şekilde değerlendirilmesi ile tomografinin meme kanseri yakalama oranlarını arttıracaktır.

Çıkar İlişkisi: Yazarlar çıkar ilişkisi olmadığını beyan eder.

\section{Kaynaklar}

1. Orel SG, Troupin RH. Nonmammographic imaging of the breast: current issues and future prospects. Semin Roentgenol 1993;28:231-241.

2. Lin WC, Hsu HH, Li CS, Yu JC, Hsu GC, Yu CP. Incidentally detected enhancing breast lesions on chest computed tomography. Korean J Radiol 2011;12:4451.

3. Swensen SJ, Jett JR, Hartman TE, Midthun DE, Sloan JA, Sykes AM. Lung cancer screening with CT: Mayo Clinic experience. Radiology 2003;226:756-761.

4. Shojaku H, Seto H, Iwai H, Kitazawa S, Fukushima W, Saito K. Detection of incidental breast tumors by noncontrast spiral computed tomography of the chest. Radiat Med 2008;26:362-367.

5. Hussain A, Gordon-Dixon A, Almusawy H, Sinha $P$, Desai $A$. The incidence and outcome of incidental breast lesions detected by computed tomography. Ann R Coll Surg Engl 2010;92:124-126.

6. Porter G, Steel J, Paisley K, Watkins R, Holgate C. Incidental breast masses detected by computed tomography: are any imaging features predictive of malignancy? Clin Radiol 2009;64:529-533.

7. Harish MG, Konda SD, MacMahon H, Newstead GM. Breast lesions incidentally detected with $\mathrm{CT}$ : what the general radiologist needs to know. Radiographics 2007;27:37-51

8. Surov A, Fiedler E, Wienke A, Holzhausen $\mathrm{HJ}$, Spielmann RP, Behrmann C. Intramammary incidental findings on staging computer tomography. Eur J Radiol 2012;81:2174-2178.

9. Bach AG, Abbas J, Jasaabuu C, Schramm D, Wienke A, Surov A. Comparison between incidental malignant and benign breast lesions detected by computed tomography: a systematic review. J Med Imaging Radiat Oncol 2013;57:529-533.

10. Inoue $M$, Sano $T$, Ashikaga $R$, et al. Dynamic multidetector CT of breast tumors: Diagnostic features and comparison with conventional techniques. AJR Am J Roentgenol 2003;181:679-686. 